\title{
PEMODELAN MATEMATIK SISTEM HIDROLIK PADA MAIN LANDING GEAR EXTENSION DAN RETRACTION PESAWATBOEING 737-900ER DENGAN PROGRAM MATLAB-SIMULINK
}

\author{
Mohammad Ardi Cahyono ${ }^{1}$, Rahmat Suwandi ${ }^{2}$ \\ Program Studi Teknik Penerbangan \\ STT Adisutjipto \\ J1. Janti blok R lanud Adisutjipto \\ mactps774@gmail.com
}

\begin{abstract}
The problem that often arises in the hydraulic system when the main landing gear is done extension and retraction is the control of the hydraulic motion and the fluid motion is very big influence on the hydraulic work process where the fluid flow must be ensured or arranged in such a way as to work properly. To overcome this problem, a mathematical modeling system is used to create a representation or an imitation of the actual system, which links the output of the system with its input in a mathematical relationship and its parameter values.

The research was conducted by observation method and literature study to obtain the data and its calculation. The results of this study obtained a description of the response and dynamic characteristics of the PID controller in the transfer function of the hydraulic system when the main landing gear extension and retraction of the nearest Boeing 737-900ER aircraft is the 5th time experiment by inputting PID controller value $P=13 I=4 D=3$ with an error value of 0.01887 and an overshoot of 1,0002 .

With a small error value or a $2 \%$ value limit and the response picture is not experiencing a large overshoot, then the picture of the response in accordance with the expected in the 5th experiment where the error value of 0.01887 and overshoot of 1,0002. With an overview of the response with this small overshoot then the accuracy of the system will stop at the point corresponding to the actual system. By using this modeling, the response of the main landing gear extension and retraction movements can be well studied thus providing a good understanding of the performance of the hydraulic system.
\end{abstract}

Keywords: mathematical modeling, main landing gear, Matlab-Simulink, PID.

\begin{abstract}
Abstrak
Permasalahan yang sering muncul pada sistem hidrolik saat main landing gear dilakukan extension dan retraction adalah pengontrolan gerak hidrolik dan gerak fluida yang sangat besar pengaruhnya pada proses kerja hidrolik dimana aliran fluida itu harus dipastikan atau diatur sedemikian rupa agar dapat bekerja dengan baik. Untuk mengatasi masalah ini, maka digunakanlah sebuah sistem pemodelan matematik yakni dengan tujuan untuk membuat representasi atau tiruan dari sistem sebenarnya, yang menghubungkan keluaran sistem dengan masukannya dalam suatu hubungan matematik dan nilai-nilai parameternya.

Penelitian dilakukan dengan metode observasi dan studi literatur untuk memperoleh data serta perhitungannya. Hasil dari penelitian ini didapatkan bahwa gambaran respon dan karakteristik dinamik dari controller PID dalam fungsi transfer pada sistem hidrolik saat main landing gear extension dan retraction pesawat Boeing 737-900ER yang paling mendekati adalah saat percobaan ke-5 dengan
\end{abstract}


menginputkan nilai controller $\mathrm{PID}$ sebesar $\mathrm{P}=13 \mathrm{I}=4 \mathrm{D}=3$ dengan nilai error sebesar 0,01887 dan overshoot sebesar 1,0002 .

Dengan nilai error yang kecil atau berada batasan nilai 2\% dan gambaran responnya tidak mengalami overshoot yang besar, maka gambaran respon yang sesuai dengan diharapkan yaitu pada percobaan ke-5 dimana nilai error yaitu sebesar 0,01887 dan overshoot sebesar 1,0002. Dan dikarenakan gambaran respon dengan overshoot kecil ini maka keakuratan sistem akan berhenti pada titik yang sesuai dengan sistem sebenarnya. Dengan menggunakan pemodelan ini maka respon dari gerakan main landing gear extension dan retraction dapat dipelajari dengan baik sehingga memberi pemahaman yang baik atas kinerja sistem hidrolik tersebut.

Kata Kunci : pemodelan matematik, main landing gear, Matlab-Simulink, PID.

\section{Pengantar}

Pesawat udara merupakan sarana transportasi yang cepat, efektif dan efisien, yang memerlukan sistem yang canggih dan memenuhi standar keamanan dan keselamatan. Salah satu sistem utama yang terdapat di dalam pesawat adalah sistem hidrolik. Sistem hidrolik menggunakan prinsip kerja menginput daya yang kecil untuk menggerakkan komponen yang dengan daya yang besar.

Penelitianbertujuan untuk membuat diagram blok model matematik sistem hidrolik saat prosesmain landing gear extension danretraction pesawat Boeing 737-900ER menggunakan program Matlab-Simulink dan menganalisa gambaran respon dan karakteristik dinamik dari controller PID dalam fungsi transfer pada sistem hidrolik saat main landing gear extension dan retraction pesawat Boeing 737-900ER.

Penelitian sebelumnya antara lain adalah Andri Yonas Syahputra (2008) penelitian dengan judul "Pemodelan Sistem Hidrolik Penggerak Flap Pesawat Boeing 737-300 Menggunakan Program Matlab-simulink 7.0.1" menggunakan metode penelitian eksperimental yaitu dengan mengamati pergerakan flap. Kemudian data yang didapat pada pengamatan itu diinputkan untuk mengetahui grafik karakteristiknya dan prediksi responnya dengan menggunakan software Matlab-Simulink. Prediksi respon diperoleh setelah blok diagram dalam sebuah sistem dirancang dan menginputkan parameter-parameter yang terdapat dalam simulink library.

Muhammad Raiyan (2013) penelitian dengan judul "Analisis Performa Landing Pesawat Terbang Boeing 737-800 Dengan Menggunakan Matlab-Simulink" menjelaskan bahwa penggambaran diagram blok dapat dibuat melalui program Matlab-Simulink dengan memasukkan input yang telah ditentukan oleh plot sebelumnya untuk menghasilkan simulasi landing pesawat terbang.Program Matlab-Simulink juga bertujuan untuk melakukan proses simulasi dan analisis terhadap performa pesawat diantaranya performa pesawat saat take off dan landing.

Penelitian yang dilakukanGalih Wicaksono (2014) dengan judul "Aplikasi Pengendalian Terbang Otomatis Modus Stabilize Pada Platform SSU-03 menggunakan software Ardupilot" menjelaskan mengenai proses instalasi terbang stabilize mode pada platform SSU-03 menggunakan software Ardu pilot, proses kalibrasi, dan proses tunning PID serta uji terbang secara manual dengan pesawat yang berada pada kondisi laik terbang. 


\section{Latar Belakang}

Permasalahan yang sering muncul pada sistem hidrolik saat main landing gear dilakukan proses extension dan retraction adalah pengontrolan gerak hidrolik dan prediksi mengenai simulasi pergerakan main landing gear pada saat dilakukan Operational Check atau adjusment test. Gerak fluidasangat besar pengaruhnya pada proses kerja hidrolik dimana aliran fluida itu harus dipastikan atau diatur sedemikian rupa agar dapat bekerja dengan baik. Selain pengaturan fluida, gerakan hidrolik yang tidak linier seperti terjadinya overlapping dan kesalahan pengeturan tekanan dan gaya di dalam sistem juga dapat mempengaruhi kerja dan fungsinya.Untuk mengatasi permasalahan yang muncul dan untuk memperoleh prediksi karakteristik, serta parameter pada sistem hidrolik saat main landing gear dilakukan prosesextension dan retraction maka digunakanlah sebuah sistem pemodelan, yaitu dengan pemodelan matematik.

Pemodelan merupakan suatu representasi atau tiruan dari sistem sebenarnya, yang menghubungkan keluaran system dengan masukannya dalam suatu hubungan matematik, representasi dari sistem yang dibuat ini akan memberikan manfaat dalam mengenal karakteristik dari sistem dan digunakan untuk memperkirakan bagaimana system akan memberikan tanggapan respon pada kondisi tertentu.

Pemodelanmatematikpadasistemhidrolikmain landing gear extension dan retraction sangat menarik untuk dikaji dan diteliti agar memperoleh pengetahuan dan pemahaman yang lebih mendalam mengenai sistem kendali dan pemodelan. Program Matlab-Simulink merupakan bahasa pemrograman yang banyak digunakan untuk perhitungan numerik, pemodelan, dan analisis data matematik.

\section{Metodologi Penelitian}

Subyek di dalam penelitian ini adalah proses main landing gear extension dan retraction pesawat Boeing 737-900ER, sedangkan yang menjadi objek penelitian adalah pemodelan matematik menggunakan program Matlab-Simulink yang meliputi karakteristik pesawat Boeing 737-900ER, sistem hidrolik pada main landing gear pesawat Boeing 737900ER, rentangan waktu main landing gear pesawat melakukan extension dan retraction, validasi waktu antara sistem sebenarnya dengan pemodelan matematik dan faktor pendukung lain yang berpengaruh terhadap pemodelan matematik ini.

Data primer berupa rekaman/video dan aircraft maintenance manual. Observasi adalah suatu metode sistematis yang digunakan untuk mengumpulkan data primer berupa rekaman/ video dengan cara melihat atau mengamati kegiatan dilapangan.

Main landing gear merupakan landing gear utama yang menopang beban pesawat dan menerima beban impact yang sangat besar saat pesawat pertama kali menyentuh daratan (touchdown), secara langsung. Main landing gear jenis twin merupakan dua buah main landing gear menyerap gaya yang besar saat pendaratan dan menahan beban atau berat pesawat dan menjadi tumpuan utama saat pertama kali menyentuh tanah (touchdown). Main landing gear juga berfungsi mengirimkan gaya untuk pengereman pada struktur pesawat. Pintu main landing gear terbuka terlebih dahulu saat landing gear dioperasikan untuk extend, lalu pintu main landing gear akan menutup kembali kedalam wheel well setelah proses retract dilakukan. 


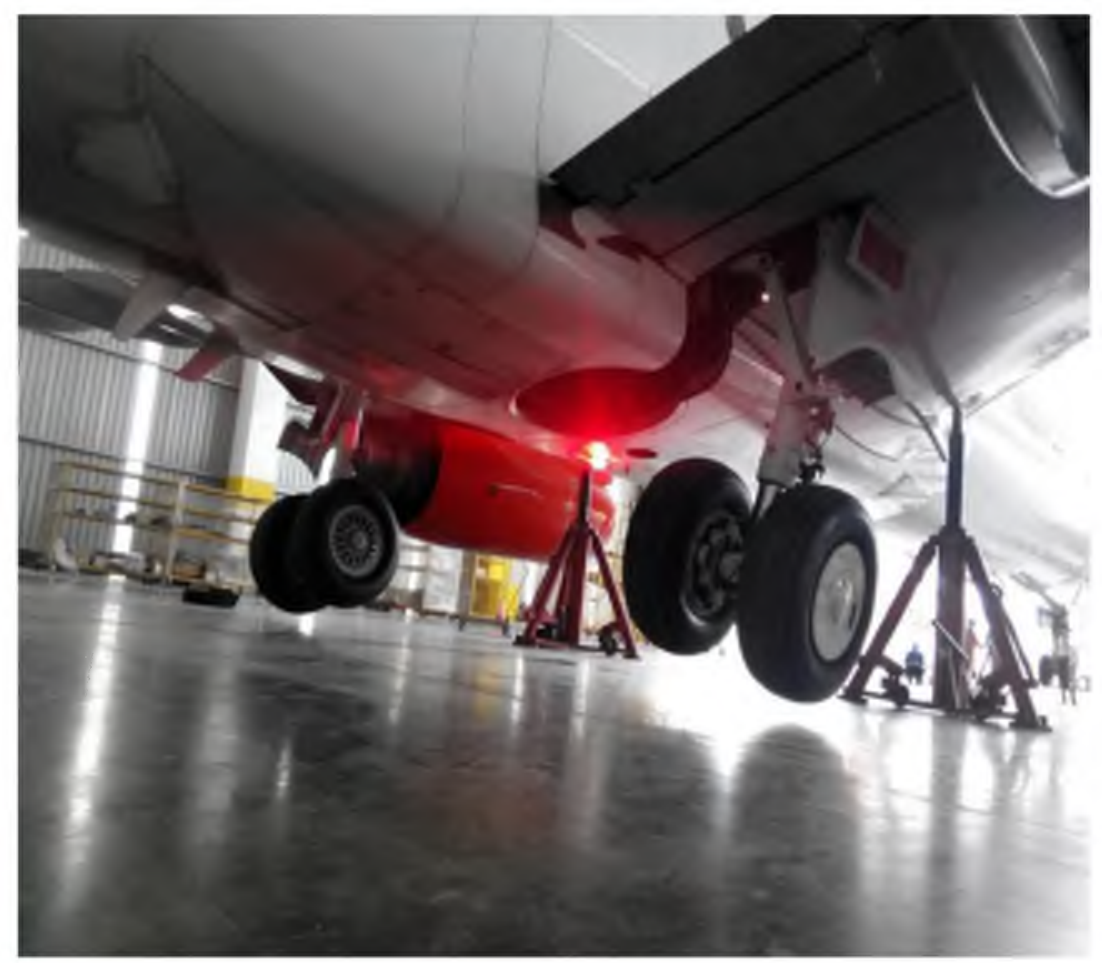

Gambar 1. Pengujian main landing gear extension dan retraction

Pesawat Boeing 737-900ER menggunakan susunan landing gear yang dilengkapi dengan tiga buah landing gear, 2 (dua) buah landing gear utama (main landing gear) dan 1 (satu) buah landing gear depan (nose landing gear).Ketiga landing gear ini merupakan tipe main landing gear main landing gear yang dapat dilakukan extension dan retraction dan ditempatkan pada wheel well atau di dalam fuselage dan dilengkapi dengan oleo pneumatic shock absorber (oil-gas filled), tubeless tire serta disc brake sebagai pendukung pada main landing gear saat dioperasikan.

Proses pengujian main landing gear extension dan retraction diantaranya yaitu memastikan main landing gear aman dari semua personel dan peralatan. Gerakan cepat dari main landing gear dapat melukai personel dan merusak peralatan. 
Alur penelitian ini adalah sebagai berikut :

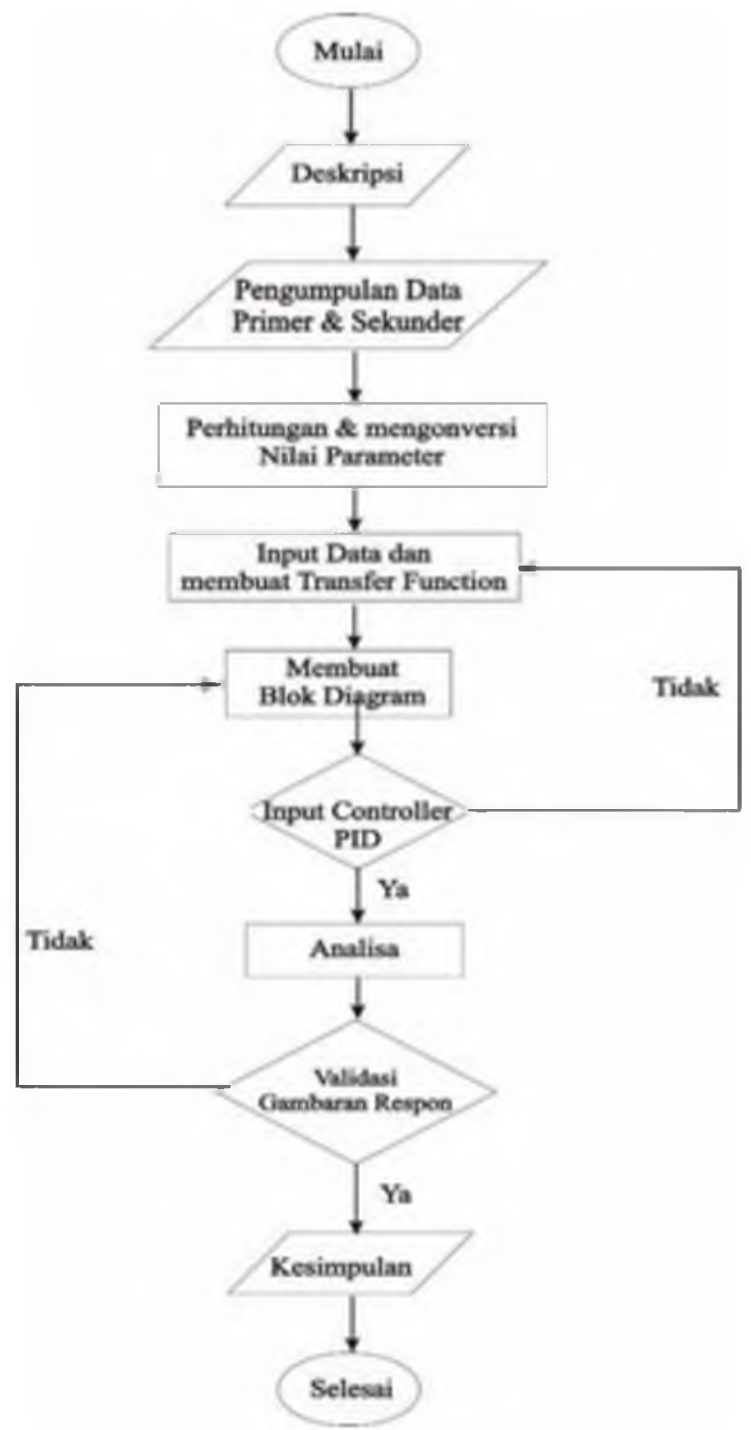

Gambar 2. Diagram Alur Penelitian

\subsection{Prinsip Kerja Sistem}

Model Matematik merupakan karakteristik dinamik suatu sistem. Dalam suatu model dapat disajikan dalam beberapa bentuk yang berbeda dan tergantung sistem yang ditinjau. Setelah model matematik suatu sistem diperoleh, berbagai perangkat analitik dan komputer seperti Matlab-Simulink dapat digunakan untuk menganalisis. Model Matematik terbagi menjadi tiga macam yakni model ikonik (visualisasi), model analog (keserupaan gejala), model matematik/simbolik (kuantitatif persamaan matematik).Hasil dari pemodelan matematik sistem hidrolik pada main landing gear ini berupa fungsi alih lingkar tertutup (closed loop transfer function) sehingga akan diamati performansi sistem hidrolik pada main landing gear saat extension dan retraction ini dalam domain 
waktu pada outputnya. Kemudian hasil performansi sistem ini dievaluasi dan divalidasi dengan sistem sebenarnya untuk mengetahui kualitas tanggapan respon dan kecepatan tanggapan serta nilai koefisien korelasinya kemudian kita dapat mengetahui apakah sudah memenuhi performansi yang diinginkan atau belum.

Fungsi alih didefinisikan sebagai perbandingan dari transformasi Laplace keluaran (fungsi respon) dan transformasi Laplace masukan (fungsi penggerak) dengan anggapan bahwa semua syarat awal adalah nol. Fungsi alih adalah suatu ekspresi yang merelasikan keluaran dan masukan suatu sistem linier parameter konstan dalam bentuk parameter sistem dan merupakan sifat dari sistem itu sendiri, tidak bergantung pada fungsi masukan atau penggerak. Fungsi alih mencakup satuan-satuan yang diperlukan untuk merelasikan masukan dan keluaran, namun fungsi alih tidak memberikan informasi mengenai struktur fisik dari sistem (berbeda namun identik).

Pada dasarnya motor servo hidrolik merupakan penguat daya hidrolik dengan pengontrolan katup pandu dan aktuator. Katup pandu (Pilot valve) adalah suatu katup imbang artinya semua gaya tekan yang bekerja padanya adalah setimbang. Keluaran daya yang sangat besar dapat dikontrol dengan katup pandu yang posisinya dapat disetel dengan daya yang sangat kecil.

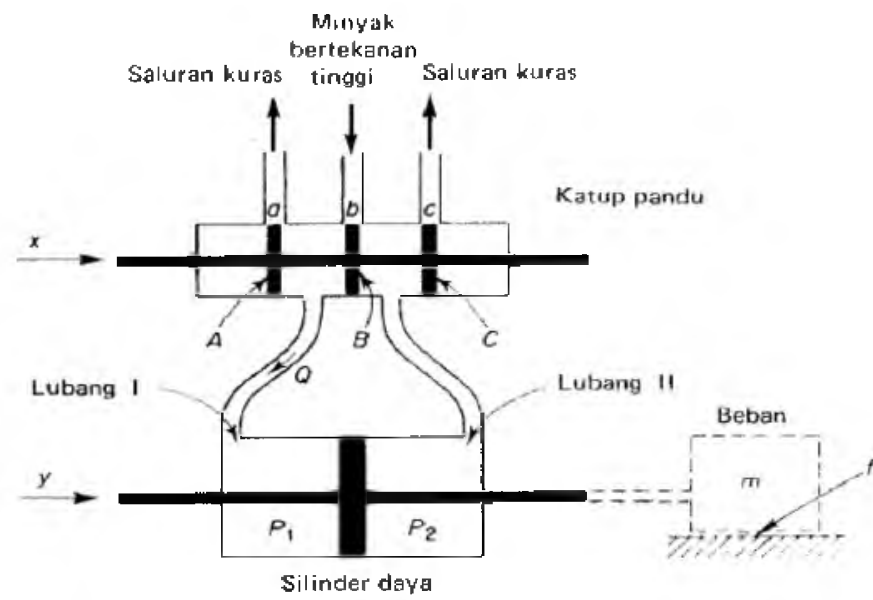

Gambar 3.Diagram Skematik Motor Servo Hidraulik

Sumber : (Katsuhiko Ogata, Modern Control Engineering Fourth Edition)

Servomotor hidrolik seperti ditunjukkan pada gambar 2.3 adalah aktuator yang dikendalikan oleh katup pandu (pilot valve). Semua gaya tekanan yang dihasilkan oleh silinder daya diatur oleh katup pandu tersebut. Operasi motor servo hidrolik pada sistem ini yaitu jika katup pandu digerakkan ke kanan maka lubang I dihubungkan dengan lubang catu, dan minyak bertekanan masuk kedalam ruang disebelah kiri torak daya. Karena lubang II dihubungkan dengan lubang kuras, maka minyak di sebelah kanan torak daya ke luar kembali. Minyak yang mengalir ke dalam silinder daya mempunyai tekanan yang tinggi sedangkan minyak yang ke luar dari silinder daya mempunyai tekanan yang rendah. Beda tekanan yang dihasilkan pada kedua sisi torak akan menyebabkan torak bergerak ke kanan. Minyak yang kembali ke saluran kuras ditekan dengan sebuah pompa kemudian disirkulasikan lagi di dalam sistem. Jika torak pandu di gerakkan ke kiri, maka torak daya akan bergerak ke kiri. Dalam prakteknya, lubang a,b, dan c yang ditunjukkan pada gambar 2.3 sering kali dibuat 
lebih lebar daripada katup a,b, dan c. Dalam hal ini, selalu terjadi kebocoran pada katup. Hal ini akan memperbaiki baik kepekaan maupun kelinieran motor servo hidraulik.

Jika Q di definisikan sebagai laju aliran minyak ke silinder daya (kg/det). $\Delta \mathrm{P}$ sebagai beda tekanan pada torak daya $\left(\mathrm{N} / \mathrm{m}^{2}\right)$ dan $\mathrm{x}$ sebagai perpindahan katup pandu $(\mathrm{m})$. Maka hubungan antara $\mathrm{Q}, \mathrm{x}$, dan $\Delta \mathrm{P}$ dapat di peroleh persaman nonlinear :

$$
Q=f(x, \Delta \mathrm{P})
$$

Dengan linearisasi persamaan nonlinear ini maka diperoleh persamaan :

$$
Q-\bar{Q}=K_{1}(x-\bar{x})-K_{2}(\Delta P-\Delta \bar{P})
$$

Perhatikan bahwa untuk sistem ini, kondisi kerja normalnya $\mathrm{Q}=0, \mathrm{x}=0$, dan $\Delta \mathrm{P}=0$.

Sehingga dapat diperoleh persamaan :

$$
Q=K_{1} x-K_{2} \Delta \mathrm{P}
$$

Diagram blok mengandung informasi perilaku dinamik tetapi tidak mengandung informasi mengenai konstruksi fisik dari sistem. Oleh karena itu, beberapa sistem yang berbeda dan tidak mempunyai relasi satu sama lain dapat dinyatakan dengan diagram blok yang sama. Detektor kesalahan menghasilkan suatu sinyal yang merupakan selisih antara sinyal masukan acuan dengan sinyal umpan balik dari system kendali.

Dashpot adalah suatu perangkat yang menimbulkan gaya viskos, atau redaman. Perangkat ini terdiri dari sebuah torak dan silinder isi minyak. Setiap gerakan relatif antara batang torak dan silinder dilawan oleh minyak karena minyak tersebut harus mengalir di sekitar torak, dari satu sisi torak ke sisi yang lain. Pada dasarnya dashpot ini menyerap energi. Energi yang diserap ini didispasikan sebagai panas, sehingga dashpot tidak menyimpan energi kinetik atau potensial.
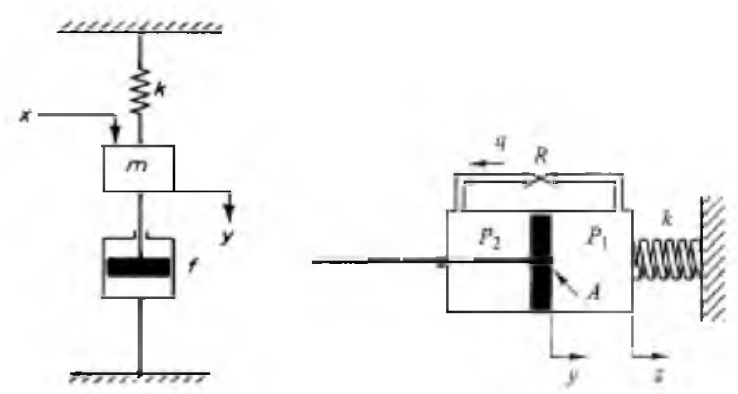

Gambar 4 Sistem Pegas,Massa, danDashpot

Sumber : (Katsuhiko Ogata, Modern Control Engineering Fourth Edition)

Sistem kontrol PID adalah jenis sistem kontrol closed loop yang banyak diaplikasikan dalam proses sistem kontrol otomatis karena kesederhanaan strukturnya yang tahan terhadap gangguan luar (noise) serta dapat diterapkan dalam kondisi operasi yang bervariasi. Tetapi kontrol PID perlu diatursecara benar agar dapat bekerja optimal, hal ini dikarenakan sistem 
kontrol PID merupakan sistem kontrol linear, yang artinya parameter-parameter ditentukan dan nilai tersebut dipertahankan tetap selama proses pengontrolan.

Sistem kontrol PID terdiri dari kontrol proportional, integral, dan derivative. Dengan mencari konstanta masing - masing untuk selanjutnya dianalisa. Fungsi alih atau keluaran respon pada sistem kontrol PID merupakan besaran yang nilainya tergantung pada nilai konstantanya. Kontrol proportional, integral, dan derivative masing-masing memiliki kelebihan dan kekurangan. Dalam implementasinya masing-masing kontrol dapat bekerja sendiri ataupun digabungkan. Dalam perancangan sistem kontol PID yang perlu dilakukan adalah mengatur parameter proportional, integral, dan derivative agar tanggapan sinyal output sistem terhadap input tertentu sebagaimana yang diinginkan.

Dalam pengendalian sistem kontrol PID biasanya dilakukan dengan metode coba-coba (trial \& error). Hal ini dikarenakan parameter $\mathrm{K}_{\mathrm{P}}, \mathrm{K}_{\mathrm{I}}$, dan $\mathrm{K}_{\mathrm{D}}$ tidak independentatau tidak tergantung pada data - data acuan lain yang berubah-ubah. Untuk mendapatkan aksi kontrol yang baik diperlukan langkah coba-coba dengan kombinasi antara proportional, integral, dan derivatives ampai ditemukan nilai $\mathrm{K}_{\mathrm{P}}, \mathrm{K}_{\mathrm{I}}$, dan $\mathrm{K}_{\mathrm{D}}$ seperti yang diinginkan. PID merupakan salah satu metode kontrol otomatis, yaitu metode kontrol yang mengatur tanggapan (respon) sistem terhadap input yang dimaksukkan. Kontrol PID terdiri dari kontrol proportional yaitu kontrol yang keluarannya sebanding dengan besarnya sinyal kesalahan (selisih antara besaran yang diinginkan dengan nilai aktualnya). Kemudian kontrol integral yaitu kontrol yang keluarannya menghasilkan respon atau tanggapan sistem yang memiliki kesalahan keadaan stabil sama dengan nol. Jika pada sebuah sistem kontrol tidak memiliki pengontrol integral, maka kontrol proportional tidak mampu menjamin keluaran sistem dengan kesalahan dan keadaan stabilnya sama dengan nol. Sehingga dibutuhkan suatu pengontrol yang mampu menutupi kelemahan kontrol proportional tersebut yaitu kontrol integral. Kemudian kontrol derivative yaitu kontrol yang mengatur kecepatan (mempercepat) respon awal suatu sistem, tetapi tidak memperkecil kesalahan pada keadaan stabil. Kontrol ini bekerja pada ruang lingkup yang sempit yaitu pada masa perubahan input. Kontrol derivative bertujuan mengantisipasi pembangkit nilai kesalahan, memberikan aksi yang bersifat korektif dan cenderung meningkatkan stabilitas sistem. Masing - masing kontrol dapat bekerja sendiri atau dikombinasikan satu sama lainnya, akan tetapi masing-masing kontrol memiliki kelebihan dan kekurangannya sendiri, oleh karena itu untuk mendapatkan suatu aksi kontrol sistem yang baik, biasanya digunakan kombinasi dari ketiga pengontrol ini.

Pada penelitian ini, kontrol PID digunakan pada sistem servo pesawat, pengontrol proportional berfungsi mengatur input yang akan diberikan kepada servo. Servo akan bereaksi sesuai dengan input yang diberikan, akan tetapi input tidak memiliki batasan sehingga untuk menjaga keadaan putaran servo yang stabil (input tidak terlalu besar atau terlalu kecil) harus dilakukan koreksi secara terus menerus. Hal ini menjadi tidak efektif, oleh karena dibutuhkan suatu pengontrol yang mengatur batasan input pada keadaan putaran servo stabil, yaitu pengontrol integral. Kontrol integral mengatur batasan input ke servo dengan cara mengoreksi kesalahan - kesalahan yang ditimbulkan oleh kontrol proportional secara terus menerus. Hal ini mengakibatkan respon sistem kontrol menjadi lambat karena setiap kali kontrol proportional memberikan input akan selalu menghasilkan kesalahan, kontrol integral langsung melakukan koreksi terhadap kesalahan tersebut sehingga membutuhkan waktu untuk mencapai keadaan kesalahan sama dengan nol. 
Oleh karena itu dibutuhkan kontrol yang dapat meningkatkan waktu respon sistem kontrol servo, yaitu kontrol derivative. Kontrol derivative sebenarnya berfungsi mengantisispasi kesalahan yang ditimbulkan oleh input dari kontrol proportional dengan cara langsung melakukan koreksi terhadap kesalahan, sehingga apabila kesalahan yang terjadi pada sistem kontrol servo dapat dikurangi maka sistem kontrol servo dapat mencapai keadaan stabil dengan lebih cepat.

Pada gambar 2.6 di bawah ini ditunjukkan bahwa diagram skematik sebuah controller proporsional, integral, derivative.

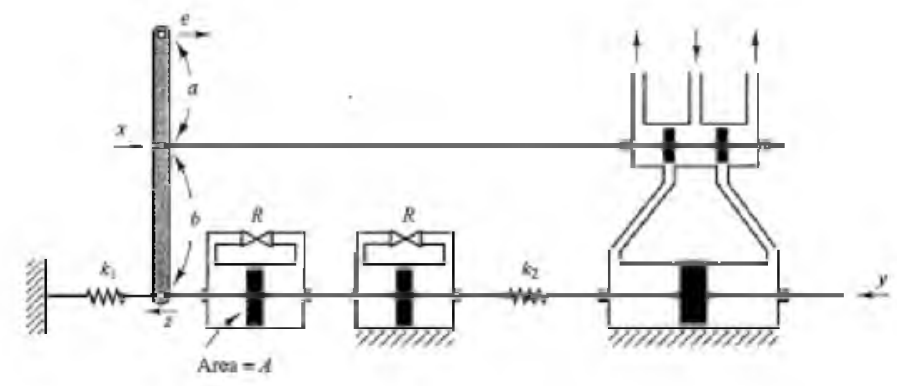

Gambar 5. Diagram Skematik Sebuah Controller Proporsional, Integral, dan Derivative Sumber : (Katsuhiko Ogata, Modern Control Engineering Fourth Edition)

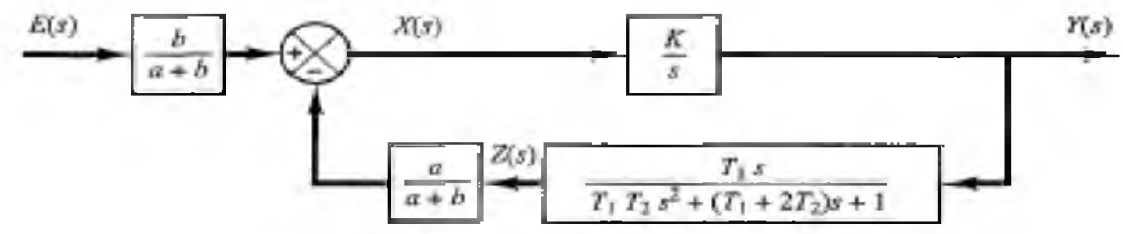

Gambar 6. Blok Diagram Sistem Hidrolik

Sumber : (Katsuhiko Ogata, Modern Control Engineering Fourth Edition)

Jika terdapat dua dashpot yang identik, maka fungsi transfer $Z(s) / Y(s)$ dapat diperoleh sebagai berikut :

$\frac{Z(s)}{Y(s)}=\frac{T_{1} s}{T_{1} T_{2} s^{2}+T_{1}+2 T_{2} s+1}$

Sebuah blok diagram untuk sistem hidrolik dengan kontrol controller proporsional, integral, derivative ditunjukkan pada gambar di atas. Dari blok diagram di atas maka diperoleh fungsi transfer $Y(s) E(s)$ sebagai berikut :

$\frac{Y(s)}{E(s)}=\frac{b}{a+b} \frac{\frac{K}{s}}{\frac{T_{1} s}{s T_{1} T_{2} s^{2}+T_{1}+2 T_{2} s+1}}$ 


$$
\begin{aligned}
\frac{Y(s)}{E(s)} & =\frac{b}{a} \frac{T_{1} T_{2} s^{2}+T_{1}+2 T_{2} s+1}{T_{1} s} \\
& =K_{p}+\frac{K_{i}}{s}+K_{d} s
\end{aligned}
$$

Di mana :

$$
\begin{aligned}
& K_{p}=\frac{b}{a} \frac{T_{1}+2 T_{2}}{T_{1}} \\
& K_{i}=\frac{b}{a} \frac{1}{T_{1}} \\
& K_{d}=\frac{b}{a} T_{2} \\
& T_{1}=\mathrm{T}=\frac{\mathrm{R} A^{2} \rho}{k}
\end{aligned}
$$

\section{Hasil dan Pembahasan}

Pada bagian ini akan membahas mengenai proses pembuatan pemodelan matematik dimulai dari menentukan nilai parameter yang akan dipakai untuk dijadikan suatu model matematik melalui persamaan fungsi transfer. Hasil dari pemodelan matematik sistem hidrolik pada main landing gear ini berupa fungsi alih lingkar tertutup (closed loop transfer function) sehingga akan diamati performansi sistem hidrolik pada main landing gear saat extension dan retraction ini dalam domain waktu pada outputnya. Kemudian hasil performansi sistem ini dievaluasi dan divalidasi grafik yang dibentuk dengan suatu batasan nilai error $2 \%$. dengan sistem sebenarnya untuk mengetahui kualitas tanggapan respon dan kecepatan tanggapan kemudian kita dapat mengetahui apakah sudah memenuhi performansi yang diinginkan atau belum.

Dalam pemodelan matematik sistem hidrolik langkah pertama yang harus dilakukan adalah menentukan parameter dari sistem hidrolik yang sebenarnya. Adapun untuk mencari nilai-nilai parameter tersebut, beberapa nilai parameternya harusdilakukan perhitungan sesuai dengan data spesifikasi pesawat yang dibuat, adapun perhitungannya adalah sebagai berikut :

Tekanan hidrolik yang terdapat pada aircraft maintenance manual sebesar 3000 psi +150psi. Diketahui bahwa 1 Psi $=6894,76 \mathrm{~N} / \mathrm{m}^{2}$ sehingga :

Tekanan hidrolik $(\mathrm{P})$ pada saat main landing gear extension dan retraction sebesar $=$ 3000 psi

$$
\begin{aligned}
& =3000 \times 6894,76 \\
& =20684280 \mathrm{~N} / \mathrm{m}^{2}
\end{aligned}
$$

Diketahui bahwa panjang diameter lingkaran pada pistonyang terdapat pada aircraft maintenance manual sebesar $15 \mathrm{~cm}$, maka jari-jari lingkarannya yaitu sebesar $7,5 \mathrm{~cm}$. Adapun perhitungan luas permukaan pada piston sebagai berikut : 


$$
\begin{aligned}
A & =\pi \cdot r^{2} \\
& =3,14 \cdot 7,5^{2} \\
& =0,0176625 \mathrm{~m}^{2}
\end{aligned}
$$

Untuk mendapatkan besar gaya yang diberikan untuk melakukan extension dan retraction, maka dengan rumus :

$$
\mathrm{F}=\mathrm{P} \times \mathrm{A}
$$

Maka gaya yang diberikan untuk proses main landing gear extension dan retraction yaitu :

$$
\begin{aligned}
\mathrm{F} & =20684280 \mathrm{~N} / \mathrm{m}^{2} \times 0,0176625 \mathrm{~m}^{2} \\
& =365336,0955 \mathrm{~N}
\end{aligned}
$$

Diketahui bahwa panjang spring sebelum merenggang yang terdapat pada aircraft maintenance manual sebesar $0,95 \mathrm{~m}$ dan panjang spring setelah merenggang yaitu $1,35 \mathrm{~m}$.

$$
\begin{aligned}
& \Delta \mathrm{x}=L_{t}-L_{0} \\
& =1,35-0,95 \\
& =0,4 \mathrm{~m}
\end{aligned}
$$

Maka nilai konstanta pegas $(k)$ main landing gear extensiondan retraction dapat diperoleh dengan persamaan:

$$
\begin{aligned}
\mathrm{F} & =k \cdot \Delta \mathrm{x} \\
k & =\frac{\mathrm{F}}{\Delta \mathrm{x}} \\
k & =\frac{365336,0955 \mathrm{~N}}{0,4 \mathrm{~m}} \\
& =913340,2388 \mathrm{~N} / \mathrm{m}
\end{aligned}
$$

Dengan mengasumsi nilai resistance to flow at the restriction (R) yaitu pada main landing gear extension sebesar 38445600000 N.s/kg dan pada main landing gear extension $26616000000 \mathrm{~N} . \mathrm{s} / \mathrm{kg}$.

Disubtitusikan ke dalam persamaan $\mathrm{T}=\frac{\mathrm{R} A^{2} \rho}{k} . \mathrm{T}_{1}$ dianggap time constant untuk main landing gear extension dan $\mathrm{T}_{2}$ dianggap time constant untuk main landing gear retraction. Kemudian diperoleh nilai Time constant $\left(\mathrm{T}_{1}\right.$ dan $\left.\mathrm{T}_{2}\right)$ yang sesuai dengan yang terdapat pada 
aircraft maintenance manual yaitu sebesar $13 \mathrm{~s}$ dan $9 \mathrm{~s}$. Maka dari nilai parameter-parameter di atas dapat diperoleh persamaan fungsi transfer sebuah sistem main landing gear extension dan retraction pada Matlab-Simulink yaitu :

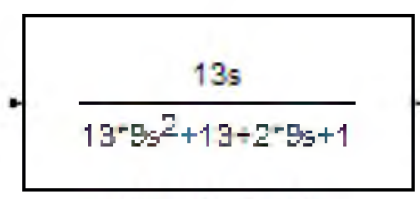

Transfer Fon 1

Gambar 7. Fungsi Transfer Main Landing Gear Extension dan Retraction

Berikut merupakan desain diagram blok dari model matematik sistem hidrolik main landing gear extension dan retraction.

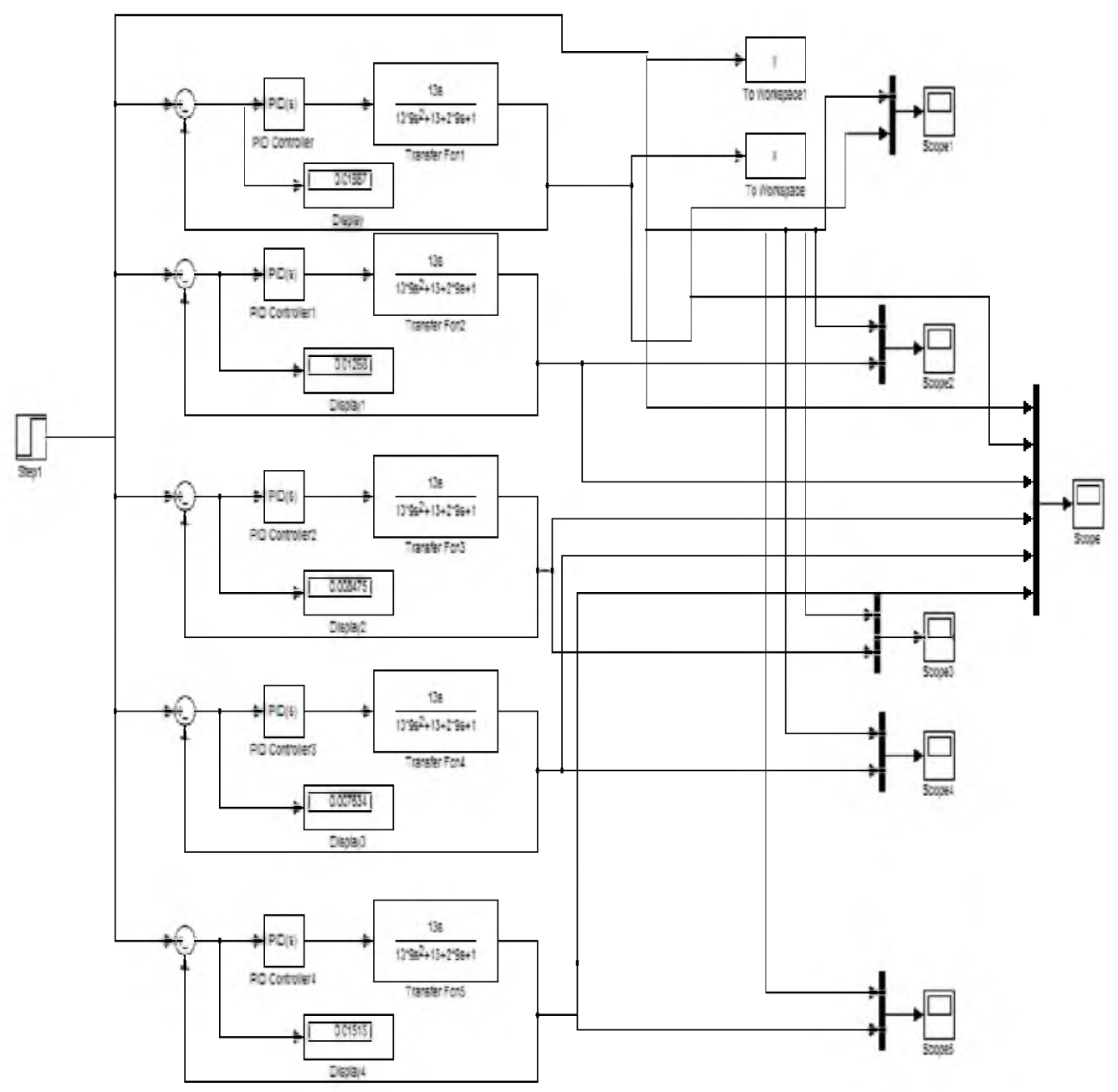

Gambar 8. Diagram Blok Pemodelan Matematik 
Gambar di atas merupakan blok diagram suatu model matematik sistem main landing gear extension dan retraction dengan controller PID dengan nilai proporsional, integral dan derivative yang dipakai yaitu pada tabel di bawah ini :

Tabel 1. Model Matematik controller PID dengan Metode trial and error

\begin{tabular}{|c|c|c|c|c|c|}
\hline Percobaan & $\mathrm{P}$ & $\mathrm{I}$ & $\mathrm{D}$ & error & overshoot \\
\hline 1 & 6 & 8 & 1 & 0,009524 & 1,21 \\
\hline 2 & 15 & 6 & 4 & 0,01268 & 1,02 \\
\hline 3 & 10 & 9 & 1 & 0,008475 & 1,13 \\
\hline 4 & 10 & 7 & 2 & 0,01087 & 1,09 \\
\hline 5 & 13 & 4 & 3 & 0,01887 & 1,0002 \\
\hline
\end{tabular}

Dari nilai - nilai tersebut maka didapatkan gambaran respon yang sesuai dan memiliki keakuratan tinggi dengan batas toleransi error sebesar $2 \%$.

Pada percobaan ke-5, dengan input $\mathrm{P}=13, \mathrm{I}=4$ dan $\mathrm{D}=3$ maka diperoleh nilai error sebesar 0,01087 , dan gambaran responnya adalah sebagai berikut :

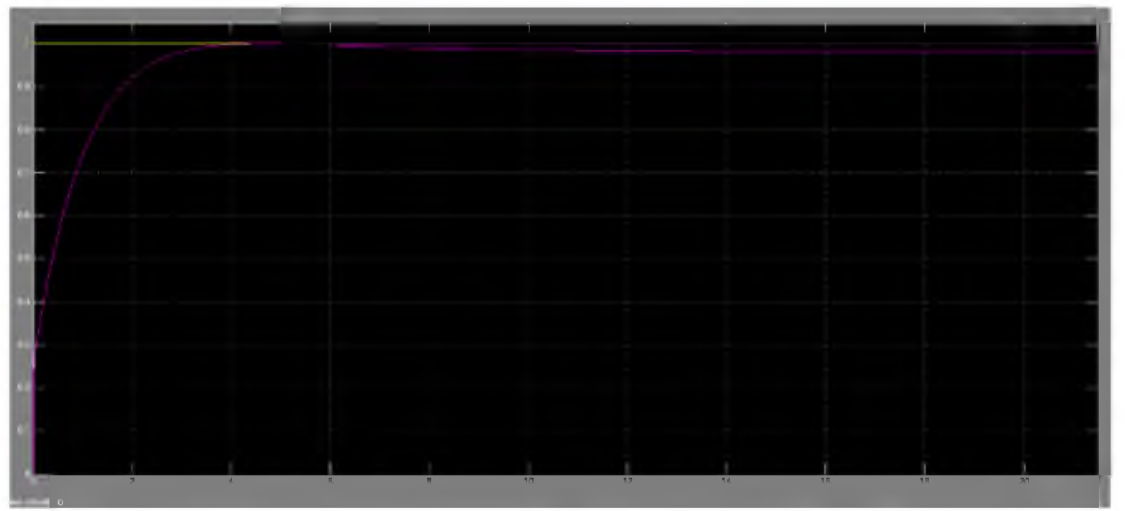

Grafik 4.6 Gambaran Respon controller PIDdengan input $\mathrm{P}=13 \mathrm{I}=4 \mathrm{D}=3$

Dari gambaran respon pada grafik $4.6 \mathrm{di}$ atas, maka terlihat bahwa dengan nilai error yaitu sebesar 0,01887 maka respon yang terjadi sesuai dengan yang diharapkan karena overshoot kecil sekali yaitu hanya sebesar 1,0002, oleh karena itu keakuratan dari pemodelan matematik yang dibuat hampir mendekati gambaran respon yang dihasilkan.

Dengan nilai error yang kecil atau berada batasan nilai $2 \%$ dan gambaran responnya tidak mengalami overshoot yang besar, maka gambaran respon yang sesuai dengan diharapkan yaitu pada percobaan ke 5 dimana nilai error yaitu sebesar 0,01887 dan overshootsebesar 1,0002. Dan dikarenakan gambaran respon yang dengan overshoot kecil ini maka keakuratan sistem akan berhenti pada titik yang sesuai dengan sistem sebenarnya.Dengan menggunakan pemodelan ini maka respon dari gerakan main landing gear extension dan retraction dapat dipelajari dengan baik sehingga memberi pemahaman yang baik atas kinerja sistem hidrolik tersebut. 


\section{Kesimpulan}

Kesimpulan penelitian ini adalah sebagai berikut :

a. Diagram blok model matematik sistem hidrolik saat prosesmain landing gear extension danretraction pesawat Boeing 737-900ER menggunakan program Matlab-Simulink yaitu dengan cara membuat suatu fungsi transfer berdasarkan nilai parameter yang terdapat pada aircraft maintenance manual dan membuat suatu rangkaian sesuai dengan tujuan lalu menentukan nilai input controller PID untuk mendapatkan grafik yang diharapkan dan mendekati dengan respon sistem yang sebenarnya, adapun diagram blok model matematiknya.

b. Gambaran respon dan karakteristik dinamik dari controller PIDdalam fungsi transfer pada sistem hidrolik saat main landing gear extension dan retraction pesawat Boeing 737-900ER yang paling mendekati adalah saat percobaan ke 5 dengan menginputkan nilai controller $P I D$ sebesar $\mathrm{P}=13 \mathrm{I}=4 \mathrm{D}=3$ dengan nilai error sebesar 0,01887 dan overshoot sebesar 1,0002 .

\section{DAFTAR PUSTAKA}

Aircraft Maintenance Manual (AMM).2015. Base Maintenance Batam Aero Technic. Batam : Boeing.

Andri Yonas Syahputra. 2008. Pemodelan sistem hidrolik penggerak flap pesawat Boeing 737 - 300 menggunakan program Matlab-Simulink 7.0.1. Yogyakarta: STTA.

Ardi Cahyono, Karseno KS. Pemodelan Sistem Hidrolik Penggerak Flap pada Pesawat Latih Dasar KT-IB Menggunakan Matlab V6.5

Galih Wicaksono. 2014. Aplikasi pengendalian terbang otomatis modus stabilize pada platform SSU-03 menggunakan software Ardupilot. Yogyakarta: STTA

Muhammad Raiyan. 2013. Analisis Performa Landing Gear Pesawat B 737-800 dengan Matlab-Simulink. Yogyakarta: STTA

Norman S.Currey. 1988. Aircraft Landing Gear Design Principles and Practies. Georgia: American Institute of Aeronautics and Astronautics, Inc.

Ogata, Katsuhiko. 2002. Modern Control Engineering Fourth Edition. Tehran: Aeeizh.

Ralph, D. Bent dan James, L McKinley. 1980. Aircraft Maintenance and Repair. California.

Thomas Wahyu Dwi Hatanto. 2004. Analisis dan Desain Sistem Kontrol dengan MATLAB. Yogyakarta : Andi 